\title{
PENERAPAN MODEL UTAUT UNTUK MEMAHAMI NIAT MENGGUNAKAN SEARCH ENGINE ADVERTISING PADA PELAKU UMKM PROVINSI BALI
}

\author{
Muhammad Azhari Dadas ${ }^{1}$ \\ Gede Bayu Rahanatha ${ }^{2}$
}
${ }^{1,2}$ Fakultas Ekonomi dan Bisnis Universitas Udayana (Unud), Bali, Indonesia email: azdadas@ymail.com

\begin{abstract}
ABSTRAK
Tujuan dari penelitian ini adalah untuk meneliti pengaruh ekspektasi kinerja, ekspektasi usaha dan faktor sosial terhadap niat menggunakan search engine advertising. Penelitian ini dilakukan terhadap Pelaku UMKM di Provinsi B gali. Kuisioner menjadi sarana pengumpulan data pada penelitian ini. Sampel penelitian adalah sebanyak 75 responden. Teknik pengolahan data dalam penelitian ini adalah Multiple Linier Regression (MLR). Berdasarkan hasil pengolahan data diketahui ekspektasi kinerja memiliki pengaruh yang positif signifikan terhadap niat menggunakan search engine advertising. Ekspektasi usaha tidak memiliki pengaruh terhadap niat menggunakan search engine advertising. Faktor sosial memiliki pengaruh yang positif signifikan terhadap niat menggunakan search engine advertising.
\end{abstract}

Kata kunci: ekspektasi kinerja, ekspektasi usaha dan faktor sosial.

\section{ABSTRACT}

The purpose of this study was to examine the effect of performance expectancy, effort expectancy and social factor on intention to use search engine advertising. This research was conducted on UMKM in Bali province. Questionnaires became a means of collecting data in this study. The study sample was 75 respondents. The data processing technique in this study is Multiple Linier Regression (MLR). Based on the results of data processing it is known that performance expectancy has a significant positive effect on intention to use search engine advertising. Effort expectancy has no influence on intention to use search engine advertising. Social factor has a significant positive effect on intention to use search engine advertising. Keywords: performance expectancy, effort expectancy and social factor. 


\section{PENDAHULUAN}

Perkembangan teknologi dan perubahan perilaku konsumsi telah menjadikan proses model bisnis semakin kompleks. Meningkatnya taraf kepuasan pelanggan, membuat perusahaan untuk lebih meningkatkan performa penggunaan, dan efissiensi biaya teknologi dalam model bisnis. Penciptaan sesuatu yang sempurna selalu berkaitan dengan teknologi (Farida \& Budi Hermana, 2005). Teknologi informasi dalam pandangan sempit menjelaskan sisi teknologi dari sebuah teknologi informasi, seperti hardware, software, database, networks dan peralatan lain. Teknologi informasi menjelaskan suatu koleksi teknologi informasi, pemakai dan manajemen bagi keseluruhan organisasi (Siswanto, 1997). Pemasaran internet menggunakan teknologi modern dan koneksi internet untuk menjangkau target pasar (Roberts \& Zahay, 2012). Perubahan perilaku telah membuka peluang bagi pemasar (Pollack, 1999). Oleh karena itu tidak mengherankan ketika Park \& Jun (2003) menyimpulkan bahwa internet merubah marketing dan perdagangan.

Pemasaran Internet menjadi cabang dari pemasaran yang paling menarik dan paling cepat berkembang. Pada tahun 2017 persentase pengguna internet di Indonesia menyentuh angka 54,23\%, yaitu dengan angka pengguna sebesar 143 juta jiwa dari total 262 juta. Pada tahun sebelumnya yaitu tahun 2016 pengguna internet hanya berjumlah 137,27 juta jiwa (APJII \& PusKaKom, 2017). Pelaku bisnis saat ini memerlukan pemanfaatan teknologi. Majunya jaringan internet saat ini memudahkan pelaku UMKM menjangkau konsumen baik dalam maupun luar negri. Pemasaran internet dijabarkan sebagai banner advertisement, direct mails, $e$ commerce, search engine marketing, social media marketing, content marketing, mobile marketing dan website (Mufti et al., 2014).

Website adalah titik awal dalam kampanye pemasaran internet dan komunikasi dengan pelanggan. Ini adalah tempat di ruang digital yang dimiliki oleh perusahaan, dimana semua informasi tentang perusahaan dan produknya dapat ditemukan. Search Engine Marketing (SEM) adalah alat untuk meningkatkan visibilitas situs website perusahaan dan membuat promosi online perusahaan lebih efektif melewati tautan iklan berbayar. Search Engine Advertising biasa disebut sebagai keyword advertising, sponsored search atau paid search. Search Engine Advertising merupakan instrumen periklanan online paling populer (Vandarajan \& Yadav, 2009).

Penelitian ini berfokus pada salah satu instrumen pemasaran internet website, yaitu Search Engine Advertising. Dalam pemasaran Internet, search engine advertisng adalah metode penempatan iklan online di halaman web yang menunjukkan hasil dari permintaan mesin pencari. Search engine advertising ditargetkan untuk mencocokkan istilah pencarian kunci (keywords) yang dimasukkan pada mesin pencari. Kemampuan penargetan ini telah berkontribusi pada daya tarik iklan pencarian untuk pengiklan. Konsumen akan sering menggunakan mesin pencari untuk mengidentifikasi dan membandingkan opsi pembelian segera sebelum membuat keputusan pembelian. Peluang untuk menyajikan kepada konsumen iklan yang disesuaikan dengan minat pembelian langsung mereka mendorong konsumen untuk mengklik iklan pencarian alih-alih hasil pencarian yang tidak dibayar, yang seringkali kurang relevan. Untuk pengguna online, search engine advertising menawarkan hasil pencarian yang sangat relevan 
berdasarkan permintaan konsumen sendiri, dengan demikian, search engine advertising dianggap kurang mengganggu daripada iklan banner atau iklan pop-up. Search engine advertising mengurangi biaya pencarian pengguna online dan meningkatkan aksesibilitas ke informasi bermanfaat dalam jangka waktu terbatas. Search engine advertising telah menjadi elemen penting dari pengalaman pengguna browsing dan pencarian informasi online di web. Setelah pengguna memasukkan kata kunci pada mesin pencari, akan keluar dua set hasil pencarian, yang disebut hasil set organik dan set search engine advertisement. Hasil organik adalah hasil dari index retrieval dan peringkat relevansi yang diterapkan oleh mesin pencari. Hasil organik ini tidak dipungut biaya bagi pemilik website, sedangkan hasil search engine advertisement, pengiklan membayar setiap klik pada iklan mereka.

Posisi pada iklan ini berdasarkan nominal penawaran tertinggi (Edelman et al., 2007). Iklan mesin pencari (SEA) didasarkan pada pendekatan relevansi tautan yang dibuat dengan kata kunci yang diketik oleh pengguna. Mesin pencari menghasilkan dua jenis tautan sebagai respons terhadap kata kunci pencari. Satu set hasil terdiri dari tautan "organik" (tidak disponsori) yang dihasilkan sebagai konsekuensi alami dari algoritma pencocokan hak milik. Set kedua dibentuk oleh tautan "sponsor" yang dikenal sebagai daftar "pay per-klick (PPC)" (Kennedy \& Kennedy, 2008). Search engine advertising ditampilkan sebagai hasil dari iklan perusahaan, organisasi, maupun individu yang membayar kata kunci yang digunakan oleh pencari dalam permintaan pencarian. Grup tautan kedua ini adalah iklan mesin pencari yang sebenarnya. Pengiklan menawar posisi dalam daftar tersebut dan membayar ketika klik terjadi pada iklan mereka. Saat ini penyedia layanan search engine advertising terdiri dari perusahaan Google, Bing, Yahoo dan lainya.

Dari perspektif konsumen, search engine advertisement adalah bentuk iklan yang bermanfaat karena kata kunci dan pesan iklan dicocokkan sesuai dengan istilah pencarian yang dimasukkan. Untuk pengiklan, search engine marketing merupakan peluang yang menarik untuk secara selektif menjangkau kelompok sasaran (Rainer \& Carsten, 2014). Pada search engine marketing pengguna dapat menargetkan calon konsumen secara spesifik berdasarkan jenis kelamin, umur, lokasi, hingga kegemaran. Pengguna juga dapat mengatur pengeluaran maksimal sesuai dengan yang mereka inginkan. Internet telah menjadi business playground utama dan saluran komunikasi yang paling populer, menciptakan aturan dan peran baru di sisi penawaran dan permintaan, serta pemasaran Internet dan e-commerce telah muncul sebagai keasyikan dan keterampilan bisnis utama di semua cabang industri (Aleksandar \& Olja, 2018). Pemanfaatan teknologi informasi saat ini sangat diperlukan bagi pelaku bisnis, mengingat masyarakat cenderung mengakses informasi melalui internet. Meningkatnya fasilitas pendukung internet seperti smartphone, jaringan internet a pelosok daerah dan meingkatnya kecepatan akses internet membuat calon konsumen dengan mudahnya mengakses informasi produk. Tidak hanya pasar lokal, pasar internasional pun dapat diakses dengan kemajuan teknologi saat ini. Menurut Badan Pusat Statistik (2016), 96,87\% dari jumlah tersebut bekerja di sektor UMKM, menyerap tenaga kerja lebih dari 114 juta orang di hampir 58 juta unit usaha. Kontribusi UMKM terhadap PDB. 
Nasional menurut harga berlaku pada tahun 2011 sebesar Rp4.321,8 triliun atau 58,05\%, sedangkan tahun 2012 sebesar Rp4.869,5 triliun atau 59,08\%. Menurut Badan Pusat Statistik (2016), 96,87\% dari jumlah tersebut bekerja di sektor UMKM, hal ini membuat sektor ini mampu menyerap lebih dari 114 juta lapangan pekerjaan. Pada tahun 2011 UMKM mampu berkontribusi sebanyak 58,05\% terhadap PDB Nasional atau sebesar Rp4.321,8 triliun. Peningkatan terjadi pada tahun 2012 dengan angka sebesar 59,08\% atau Rp4.869,5 triliun.

Pengelompokan UMKM dibagi berdasarkan 3 golongan. Golongan usaha mikro dengan karakteristik memiliki total aset bersih yang kurang dari 50 juta rupiah. Golongan usaha kecil dengan karakteristik memiliki total aset bersih dari 50 juta hingga 500 juta. Golongan usaha menengah dengan karakteristik memiliki total aset bersih dari 500 juta hingga 10 miliar. Di Indonesia, Undang-Undang yang mengatur tentang Usaha Mikro, Kecil, dan Menengah (UMKM) adalah UndangUndang Nomor 20 Tahun 2008. Dalam undang-undang tersebut UMKM dijelaskan sebagai: "Sebuah perusahaan yang digolongkan sebagai UMKM adalah perusahaan kecil yang dimiliki dan dikelola oleh seseorang atau dimiliki oleh sekelompok kecil orang dengan jumlah kekayaan dan pendapatan tertentu." Pemerataan perekonomian, dan peningkatan ekonomi rakyat dapat ditekan dengan pengembangan UMKM (Wirawan et al., 2015).

Penelitian terdahulu menyebutkan bahwa UMKM di beberapa daerah di Indonesia masih belum dapat memanfaatkan teknologi internet untuk kegiatan bisnisnya dengan baik, namun kebanyakan dari UMKM memiliki keinginan menggunakan internet untuk kegiatan bisnisnya dan mereka sadar akan pentingnya peran internet di dalam kegiatan bisnisnya (Prastika \& Purnomo, 2014). Penelitian yang dilakukan oleh Lembaga Deloite pada tahun 2016 menjunjukan bahwa, UMKM di beberapa daerah di Indonesia masih belum memanfaatkan teknologi internet dengan baik, hanya sembilan persen dari total UMKM yang serius untuk menjual produknya secara online melewati media sosial maupun platform perdagangan online. $18 \%$ hanya melewati media sosial. $36 \%$ UMKM memiliki akses internet, tetapi memilih untuk tidak menjual produknya secara online. $37 \%$ dari total 57,9 juta UMKM bahkan tidak memiliki akses internet.

Tabel 1.

Peringkat Indeks Daya Saing per Provinsi di Indonesia

UMKM Tahun 2012

\begin{tabular}{lcc}
\hline \multicolumn{1}{c}{ Provinsi di Indonesia } & IDS Tahun 2011 & Peringkat \\
\hline Nusa Tenggara Timur & 73,47 & 1 \\
Bali & 58,60 & 7 \\
Papua & 44,19 & 9 \\
DKI Jakarta & 29,10 & 17 \\
Jawa Barat & 14,56 & 27 \\
Riau & 2,87 & 33 \\
\hline
\end{tabular}

Sumber: BAPPENAS, 2012 
Tabel 2.

Peringkat Indeks Produktivitas per Provinsi di Indonesia UMKM Periode 2012

\begin{tabular}{lcc}
\hline \multicolumn{1}{c}{ Provinsi di Indonesia } & IDS Tahun 2011 & Peringkat \\
\hline Nusa Tenggara Timur & 0,00 & 33 \\
Bali & 13,39 & 15 \\
Papua & 25.52 & 6 \\
DKI Jakarta & 100,0 & 1 \\
Jawa Barat & 27,09 & 4 \\
Riau & 15,42 & 11 \\
\hline
\end{tabular}

Sumber: BAPPENAS, 2012

Provinsi Bali menempati peringkat 7 nasional dalam Indeks Daya Saing UMKM per provinsi. Indeks Daya Saing (IDS) Nasional ini menunjukan kerentanan dari peran UMKM di Pasar. Tingginya indeks Daya Saing Nasional di Provinsi Bali ini merupakan hal positif karena mencerminkan peluang yang baik bagi UMKM karena tingginya pariwisata dan kecintaan akan produk lokal. Sementara itu, produktivitas UMKM di Bali termasuk rendah dengan menduduki peringkat ke 15. Kepulauan Indonesia bagian tengah dan timur memiliki indeks daya saing UMKM yang tinggi. Saat ini perilaku masyarakat saat mencari informasi adalah dengan mengakses internet, hal ini membuat pemanfaatan internet bagi pelaku bisnis merupakan hal yang penting untuk dilakukan. Model pemanfaatan dan penggunaan teknologi informasi telah banyak dikembangkan oleh para peneliti. Venkatesh \& Zhang (2016) melakukan penelitian mengenai Unified Theory of Acceptance and Use of Technology (UTAUT). Penelitian dilakukan untuk mereview dan menggabungkan beberapa model penerimaan teknologi informasi dan menghipotesiskan ekspektasi kinerja, ekspektasi usaha, dan faktor sosial terhadap niat menggunakan teknologi informasi. UTAUT telah menjadi model yang umum digunakan untuk meneliti niat menggunakan. Model UTAUT ini dikonstruksi dari 8 teori sebelumnya yakni Theory of Reasoned Action (TRA), Technology Acceptance Model (TAM), Motivational Model (MM), Theory of Planned Behhavior (TPB), combined TAM and TPB, Model of PC Utilization (MPTU), Innovation Diffusion Theory (IDT) dan Social Cognitive Theory (SCT) yang dikaji lebih lanjut sehingga menghasilkan variabel-variabel yang berpengaruh terhadap intensitas dan perilaku penggunaan teknologi (Venkatesh et al., 2003).

UTAUT merupakan salah satu model adopsi terhadap teknologi yang merupakan pengembangan dari model adopsi sebelumnya, seperti TPB, TRA, dan TAM (Hakim \& Nurkamid, 2017). UTAUT telah diidentifikasi sebagai model paling komprehensif dalam mengatasi keterbatasan model penerimaan teknologi (TAMs) yang tersedia. (Yeow et al., 2009). Di dalam model UTAUT terdapat variabel-variabel utama seperti ekspektasi kinerja, ekspektasi usaha, faktor sosial dan kondisi fasilitas (Venkatesh et al., 2016). Jadi dapat disimpulkan bahwa model UTAUT merupakan model yang paling tepat untuk meneliti niat menggunakan search engine advertising. Penelitian ini menggunakan ekspektasi kinerja, ekspektasi usaha dan faktor sosial dari model UTAUT untuk meneliti niat menggunakan search engine advertising. 
Peningkatan adopsi teknologi seluler dan komunikasi seiring dengan pertumbuhan pasar online telah secara signifikan mengubah lanskap kompetitif banyak industri. Perusahaan telah menemukan cara baru untuk menjangkau pelanggan yang mengarah ke peluang baru dalam pemasaran (Chong et al., 2010). Faktor-faktor menonjol yang mempengaruhi perkembangan tersebut adalah jangkauan geografis yang luas (Laudon \& Laudon, 2002), kenyamanan penggunaan dan kemampuan komunikasi interaktif (Chaffey, 2004). Salah satu cara di mana internet telah memungkinkan pemasar adalah melalui search engine advertising (Edelman et al., 2007). Perusahaan dapat beriklan di search engine advertisment ini dengan menawar kata kunci pencarian, dalam lelang yang dilakukan oleh search engine setiap kali pengguna membuat permintaan pencarian. Iklan ditampilkan di daftar berbayar berdasarkan kecocokannya dengan kata kunci pengguna. Pengiklan membayar search engine advertisement hanya ketika pengguna mengklik iklan mereka (Sharma et al., 2017). Perdagangan yang ditingkatkan secara digital akan lebih banyak diadopsi. Pemasar tidak hanya perlu mencari peluang untuk menggunakan teknologi untuk meningkatkan penawaran, tetapi juga harus memastikan melindungi posisi kompetitif mereka (Chaffey \& Chadwick, 2016).

Niat menggunakan adalah ukuran dari probabilitas bahwa seseorang akan terlibat dalam perilaku tertentu. Seorang individu akan melakukan suatu perilaku jika mempunyai keinginan atau minat untuk melakukannya (Jogiyanto, 2007). Menurut Venkatesh et al. (2012) niat menggunakanu adalah sejauh mana seseorang telah merumuskan rencana secara sadar untuk melakukan atau tidak melakukan perilaku tertentu di masa depan. Shin (2010) mengatakan bahwa minat atau intention merupakan prediktor terbaik, dimana intention adalah representasi kognitif dari kesiapan seseorang untuk melakukan suatu perilaku tertentu. Suatu keinginan pelaku usaha UMKM di Bali untuk menggunakan search engine advertising dapat didefinisikan sebagai niat menggunakan.

Ekspektasi kinerja mengacu pada keyakinan bahwa pengguna akan mendapatkan manfaat seperti peningkatan produktivitas, efisiensi, dan penghematan waktu sebagai akibat ketersediaan dan kustomisasi informasi dengan menggunakan internet marketing (Srinivansa et al., 2002). Ekspektasi Kinerja sebagai tingkat dimana seseorang mempercayai dengan menggunakan sistem tersebut akan membantu orang tersebut untuk memperoleh keuntungan-keuntungan kinerja pada pekerjaan. Sejauh mana seseorang percaya bahwa menggunakan sistem akan membantunya untuk mencapai keuntungan dalam kinerja pekerjaan (Venkatesh \& Zhang, 2016). Menurut Mustaqim et al. (2018). ekspektasi kinerja yaitu pengguna mampu memahami tentang kemajuan teknologi informasi saat ini. Berdasarkan Venkatesh et al. (2003) ekspektasi kinerja dapat dinilai dari perceived usefulness, job-fit, relative advantage, outcome expectation, dan extrinstic motivation. Brown et al. (2016) ekspektasi kinerja adalah sejauh mana penggunaan teknologi akan memberikan manfaat bagi konsumen dan mengarah pada peningkatan kinerja. Penelitian sebelumnya menunjukkan bahwa ekspektasi kinerja adalah prediktor niat menggunakan teknologi informasi dan efektif membentuk niat individu untuk menggunakan teknologi baru (Zhou, 2011). Penelitian yang dilakukan peneliti-peneliti terdahulu menghasilkan hasil yang berbeda. Penelitian oleh Tan et al. (2013) menghasilkan pengaruh yang positif dan juga signifikan 
antara ekspektasi kinerja dan niat menggunakan pemasaran internet. Isa \& Wong (2015) memperkuat dengan hasil penelitian yang sejalan mengenai penggunaan internet di Malaysia. Penelitian dengan hasil berbeda ditunjukan oleh Singh (2015) yang menunjukan bahwa tidak adanya hubungan antara ekspektasi kinerja dengan niat menggunakan pemasaran internet di kota Chandigarth, India. Penelitian lainya pada UKM di Kota Kudus yang dilakukan oleh Hakim \& Nurkamid (2017) menghasilkan bahwa ekspektasi kinerja tidak berpengaruh terhadap niat menggunakan internet marketing pada UKM di Kota Kudus, hal ini menunjukkan bahwa para pelaku UKM masih belum memiliki keyakinan yang tinggi mengenai dampak positif (manfaat) penggunaan perdagangan internet bagi kinerja usaha mereka, karena selama ini pekerjaan promosi dan penjualan sebagian masih berbasis di rumah masing-masing. Hal ini dimungkinkan para pelaku belum mencoba menggunakan aplikasi perdagangan digital sehingga manfaatnya belum dapat dirasakan secara nyata.

Ekspektasi usaha merupakan tingkat kemudahan penggunaan sistem informasi yang akan mengurangi upaya (tenaga dan waktu) dalam melakukan pekerjaannya (Venkatesh et al., 2003). Berdasarkan Venkatesh et al. (2003) ekspektasi usaha dapat dinilai dari perceived ease of use, ease of use, dan complexity. Tingkat kemudahan yang terkait dengan penggunaan sistem (Venkatesh et al., 2010). Sejauh mana pengguna menemukan teknologi mudah dipelajari dan digunakan (Yu, 2012). Ekspektasi usaha juga dapat diartikan sebagai kemudahan penggunaan sistem yang dirasakan pengguna (Mufti et al., 2014). Tingkat kemudahan untuk menggunakan suatu teknologi didefinisikan sebagai ekspektasi usaha (Venkatesh et al., 2012). Beberapa studi sebelumnya mendukung bahwa variabel ekspektasi usaha secara signifikan berpengaruh dalam membentuk niat individu menggunakan teknologi baru (Zhou et al., 2010). Perbedaan hasil ditemui penelitian yang dilakukan peneliti-peneliti terdahulu. Madigan et al. (2016) menghasilkan adanya pengaruh signifikan dan positif antara ekspektasi usaha dan niat menggunakan, penelitian didukung oleh penelitian Tan et al. (2013) yang meneliti pada pengguna internet di Korea Selatan. Penelitian dengan hasil berbeda ditunjukan oleh Singh (2015) yang menunjukan bahwa tidak adanya hubungan antara ekspektasi kinerja dengan niat menggunakan pemasaran internet di kota Chandigarth, India.

Faktor sosial didefinisikan sebagai sejauh mana seseorang merasa bahwa orang lain yang dirasa penting percaya bahwa dia harus menggunakan sistem yang baru (Venkatesh et al., 2003). Sejauh mana seorang individu merasa percaya dia harus menggunakan sistem, dari orang lain yang dirasa penting (Venkatesh et al., 2010). faktor sosial disebut sebagai pengaruh oleh kelompok sebaya dan sekitarnya untuk memanfaatkan layanan. Menurut Mufti et al. (2014) menyatakan bahwa faktor sosial dari lingkungan sekitar sangat mempengaruhi penerimaan teknologi ataupun sistem baru. Faktor sosial merefleksikan pengaruh opini pembuat keputusan terhadap perilaku pengguna Individu. Berdasarkan Venkatesh et al. (2003) faktor sosial dapat dinilai dari subjective norm, image, dan social. Pengguna cenderung mematuhi pendapat pembuat keputusan penting lainnya. Orang-orang yang terkait erat, teman, kolega, dan sebagainya mempengaruhi niat individu menggunakan sistem berbasis Website. Peneliti-peneliti terdahulu menunjukan 
terdapat perbedaan haisl penelitian. Penelitian yang dilakukan Singh (2015), Madigan et al. (2016) menghasilkan adanya pengaruh signifikan dan positif antara faktor sosial dan niat menggunakan. Hasil penelitian berbeda ditunjukan oleh Tan et al. (2013), Isa \& Wong (2015).

Melihat rendahnya produktivitas UMKM di Provinsi Bali dan terdapatnya perbedaan hasil antara penelitian diberbagai daerah membuat variabel ekspektasi kinerja, ekspektasi usaha dan faktor sosial dirasa perlu untuk diteliti. Rumusan masalah dapat kita dapatkan dari latar belakang dan rumusan msalah diatas yaitu. 1) Apakah ekspektasi kinerja berpengaruh terhadap niat menggunakan search engine advertising pada UMKM di Provinsi Bali. 2) Apakah ekspektasi usaha berpengaruh terhadap niat menggunakan search engine advertising pada UMKM di Provinsi Bali. 3) Apakah faktor sosial berpengaruh terhadap niat menggunakan search engine advertising pada UMKM di Provinsi Bali.

Penelitian yang dilakukan ini berujuan untuk menambah pembahasan bukti empiris tentang studi hubungan antara faktor sosial, ekspektasi usaha, ekspektasi kinerja dan niat menggunakan. Pembahasan penelitian ini diharapkan dapat miningkatkan minat pelaku bisnis UMKM untuk mengaplikasikan search engine advertising, bagi pelaku bisnis penyedia layanan internet maupun jasa pemasaran untuk mengetahui niat pelaku UMKM dalam menggunakan search engine advertising.

Shin (2010) mengatakan bahwa minat merupakan gambaran kognitif dari individu mengenai kesiapanya dalam memutuskan perilaku tertentu yang individu tersebut rencanakan. Niat menggunakan adalah ukuran dari probabilitas bahwa seseorang akan melakukan perilaku tertentu. Jika seseorang mempunyai keinginan untuk melakukan sesuatu maka individu tersebut akan melakukanya. Venkatesh \& Zhang (2016) menyatakan bahwa niat menggunakan adalah kondisi suatu individu yang pada suatu taraf tertentu merumuskan untuk melakukan perilaku tertentu.

Brown et al. (2016) mengatakan bahwa ekspektasi kinerja adalah sejauh mana penggunaan teknologi akan memberikan manfaat bagi konsumen dan mengarah pada peningkatan kinerja. Ekspektasi kinerja merupakan konstruksi multidimensi yang berkaitan dengan persepsi individu tentang kecocokan pekerjaan, kegunaan, ekspektasi hasil, motivasi ekstrinsik, dan keuntungan relatif Kepercayaan dalam menggunakan suatu system tersebut dapat menignkatkan keuntungan pekerjaan dapat diartikan sebagai Ekspektasi Kinerja. Isa \& Wong (2015) menunjukan ekspektasi kinerja berpengaruh signifikan dan positif di Malaysia. Penelitian lainya pada UKM di Kota Kudus yang dilakukan oleh Hakim \& Nurkamid (2017) menghasilkan bahwa tidak adanya pengaruh antara ekspektasi kinerja dan niat menggunakan internet marketing pada UKM di Kota Kudus, saat ini pelaku UMKM di Kota Kudus hanya melakukan pemasaran dan penjualan pada rumah masing-masing tanpa platform digital, hal ini dapat memberikan arti bahwa Pelaku UMKM di Kota Kudus belum memiliki keyakinnan yang cukuptinggi mengenai manfaat internet marketing bagi penginkatan produktivitas pemasaran dan peningkatan penjualan bisnis. Belum adanya pengalaman akan manfaat pemasaran digital adalah factor yang menyebapkan kondisi ini. Berangkat dari pembahasan penelitian-penelitian terdahulu, maka penyusunan hipotesis dapat rumuskan sebagai berikut. 
$\mathrm{H}_{1}$ : Ekspektasi kinerja berpengaruh positif signifikan terhadap niat menggunakan search engine advertising

Kemudahan suatu individu dalam menggunakan suatu sistem dapat diartikan sebagai ekspektasi usaha. Tan et al. (2013) juga melakukan penelitian serupa sebelumnya yang menunjukan di Korea Selatan, ekspektasi usaha berpengaruh positif signifikan terhadap niat menggunakan pemasaran internet, sedangkan di Malaysia menunjukan tidak adanya pengaruh. Sebelumnya Madigan et al., (2016) yang melakukan penelitian pada 2016 menunjukkan hasil yang berlawanan, bahwa ekspektasi usaha berpengaruh positif dan berpengaruh signifikan terhadap niat menggunakan. Pada penelitian yang dilakukan Hakim \& Nurkamid (2017) pada UKM di Kota Kudus terlihat bahwa pengaruh ekspektasi usaha yang signifikan positif, menunjukkan bahwa faktor persepsi yang positif terhadap perdagangan digital sangat berpengaruh pada penggunaan aplikasi perdagangan digital itu sendiri. Singh (2015) yang melakukan penelitian di India mendapatkan hasil bahwa ekspektasi usaha memiliki pengaruh positif dan signifikan di Kota Delhi dan Chandigart. Penyusunan hipotesis dapat dilakukan berdasarkan kajian empiris yang telah dijabarkan, yaitu.

$\mathrm{H}_{2}$ : Ekspektasi usaha berpengaruh positif signifikan terhadap niat menggunakan search engine advertising

Menurut Venkatesh \& Zhang (2016) kondisi dimana seseorang merasa perlu merekomendasikan suatu system terbaru kepada orang lain yang menurutnya berpengaruh pada kehidupanya dapat diartikan sebagai faktor sosial. Penelitian yang dilakukan sebelumnya oleh Oswar, Suhendra, \& Harmoni (2008) yang meneliti penerimaan teknologi informasi pada usaha UMKM di Indonesia menunjukan terdapat pengaruh yang sangat nyata dari variabel prediktor terhadap tingkat penggunaan teknologi informasi. Dari variabel-variabel prediktor, variabel yang mempunyai hubungan terkuat adalah variabel faktor sosial. Penelitian yang dilakukan sebelumnya oleh Isa \& Wong (2015) menunjukan di Malaysia faktor sosial berpengaruh positif dan signifikan terhadap niat menggunakan pemasaran internet, sedangkan di Taiwan menunjukan hasil yang sebaliknya. Penelitian yang dilakukan sebelumnya oleh Tan et al. (2013) menunjukan tidak adanya pengaruh antara faktor sosial terhadap niat menggunakan pemasaran internet di Negara Malaysia dan Korea Selatan. Singh (2015) yang melakukan penelitian di India mendapatkan hasil bahwa faktor sosial berpengaruh positif dan signifikan terhadap niat menggunakan pemasaran internet di kota Delhi dan Chandigart. Penelitian dari Madigan et al. (2016) membuktikan bahwa adanya hubungan positif dan signifikan antara faktor sosial dengan niat menggunakan.

Pada penelitian yang dilakukan Hakim \& Nurkamid (2017) pada UKM di Kota Kudus terlihat bahwa faktor sosial tidak berpengaruh terhadap niat menggunakan secara signifikan. Hal ini dimungkinkan sebagai efek lanjutan dari kurangnya pemanfaatan aplikasi perdagangan internet oleh para pelaku usaha sehingga dukungan dan pengaruh dari pelaku UKM lain secara sosial masih sangat rendah, karena masih sedikit diantara mereka yang menggunakan aplikasi perdagangan internet. 
$\mathrm{H}_{3}$ : Faktor sosial berpengaruh positif signifikan terhadap niat menggunakan search engine advertising

\section{METODE PENELITIAN}

Pengadopsian teori unified of acceptance and use of technology as the underpinning theory pada penelitian asosiatif ini dilakukan untuk menaksir niat menggunakan search engine advertising. Variabel dalam penelitian asosiatif ini merupakan objek dari peenlitian ini, sedangkan subjek dalam penelitian ini merupakan pelaku UMKM di provinsi Bali yang belum menggunakan search engine advertising. Populasi penelitian ini meliputi pelaku UMKM di Provinsi Bali yang jumlahnya tidak dapat di tentukan secara pasti. Sampel dalam penelitian ini adalah pelaku UMKM di Provinsi Bali yang telah mengetahui tetapi belum pernah menggunakan search engine advertising. Penelitian ini dilakukan di Provinsi Bali. Lokasi ini dipilih karena Provinsi Bali memiliki indeks daya saing yang tinggi dengan angka 58,60, sebaliknya memiliki indeks produktivitas UMKM yang rendah dengan angka 13,39. Nonprobability sampling dan teknik Purposive sampling dipilih menjadi metode penentuan sampel pada penelitian asosiatif ini. Kriteria dalam menentukan responden pada penelitian adalah pemilik atau managerial UMKM yang lokasi usahanya di Provinsi Bali, minimal umur 17 tahun yang berpendidikan minimal SMA/SMK sederajat. Pertimbangan ini digunakan pada penelitian ini dikarenakan syarat pendirian usaha yaitu minimal 17 tahun, dan juga responden dengan minimal Pendidikan SMA/SMK sederajad dianggap dapat memahami dan mengerti isi dari kuesioner. Telah mengetahui tetapi belum menggunakan search engine advertising dan telah mengkuti komunitas bisnis baik offline maupun online.

Variabel penelitian yang digunakan dalam penelitian ini dikelompokkan menjadi variabel terikat (eksogen) dan variabel bebas (endogen). Variabel bebas merupakan variabel penelitian yang bisa memberikan pengaruh secara langsung ataupun tidak langsung terhadap variabel terikat. Sedangkan variabel terikat adalah variabel yang dipengaruhi oleh variabel bebas atau variabel yang tercipta karena adanya variabel bebas. Dalam penelitian ini ekspektasi kinerja $\left(\mathrm{X}_{1}\right)$ menjadi variabel bebas pertama dan ekspektasi usaha $\left(\mathrm{X}_{2}\right)$ menjadi variabel bebas kedua, faktor sosial $\left(\mathrm{X}_{3}\right)$ menjadi variabel bebas ketiga dan niat menggunakan search engine advertising (Y) sebagai variabel terikat.

Pendapat dari responden terhadap pertanyaan dalam kuesioner merupakan data kualitatif pada penelitian ini. Pada data kuantitatif berupa data mengenai persentase indeks daya saing dan produktivitas UMKM di Indonesia tahun 2012. Tanggapan responden dalam kuesioner penelitian merupakan sumber data premier pada penelitian ini. Publikasi data terkait dengan topik penelitian ini yang telah dipublikasikan suatu institusi merupakan data sekunder.

Penyebaran kuesioner secara bertemu langsung yang dilakukan oleh peneliti merupakan metode pengumpulan data dalam penelitian. Kuesioner penelitian ini diukur dengan menggunakan skala Likert, yaitu pilihan jawaban responden diberi nilai dengan skala lima poin. Pengujian validitas dan juga reliabilitas dilakukan agar kuesioner layak untuk digunakan sebagai sumber data. Data didapat dari 75 orang responden yang telah sesuai dengan syarat pengujian validitas dan realibilitas. 
Pemilihan jumlah responden berdasarkan teori yang dipaparkan Tabachnick \& Fidell (2013) yang menyatakan bahwa pada regresi linier berganda sampel minimal yang dipurlukan adalah harus lebih besar dari lima puluh ditambah delapan dikali jumlah variabel bebas pada penelitian. SPSS for wondows merupakan software yang menurut peneliti dirasa tepat dalam pengujian validitas. Menurut Sugiyono (2017:188) Variabel terukur dapat dinyatakan sebagai variabel yang valid apabalila output koefisien korelasi (r) hitung yang nominalnya lebih besar atau sama dengan 0,3. Software ini dipilih karena dianggap memiliki tampilan yang baik dan fitur yang lengkap. SPSS for windows juga dilengkapi dengan fitur pengukuran reliabilitas, pengukuran ini menggunakan metode statistik uji Cronbach Alpha $(\alpha)$. Output Cronbach Alpha padasoftware ini apabila melebihi 0,70 dapat diartikan bahwa variabel-variabel pada penelitian merupakan variabel yang reliable.

Penelitian kali ini, mendeskripsikan karakteristik responden dan variable penelitian menggunakan teknik descriptive analysist technict. Analisis deskripsi ini bertujan untuk membuat kesimpulan dengan memanfaatkan metode mendeskripsikan data yang telah terkumpul (Sugiyono, 2017:169). Analisis statistik deskriptif adalah perhitungan statistik, baik menggambarkan karakteristik sampel maupun hubungan antarvariabel dalam sampel. Statistik deskriptif hanya meringkas serangkaian pengamatan sampel. Statistik deskriptif merupakan media untuk mendeskripsikan data dalam bentuk dikelola.

Intisari yang sesuai denga kondisi populasi pada penelitian ini dapat dibuat dengan menggunakan teknik analisis statistik inferensial (Sugiyono, 2017:147). Bentuk statistik inferensial pada penelitian ini adalah Multilinier Regresion. Multilinier Regresion melihat pengaruh ekspektasi kinerja, ekspektasi usaha, dan faktor sosial, terhadap niat menggunakan search engine advertising. Persamaan berikut dihasilkan dari model regresi pada penelitian:

$$
\mathrm{Y}=\mathrm{a}+\mathrm{b}_{1} \mathrm{X}_{1}+\mathrm{b}_{2} \mathrm{X}_{2}+\ldots+\mathrm{b}_{\mathrm{n}} \mathrm{X}_{\mathrm{n}}+\mathrm{e}
$$

Keterangan:

Y: Niat menggunakan

$\mathrm{X}_{1}$ : Ekspektasi Kinerja

$\mathrm{X}_{2}$ : Ekspektasi Usaha

$\mathrm{X}_{3}$ : Faktor Sosial

a: Konstanta

b: Koefisien Regresi

e: Erro

\section{HASIL DAN PEMBAHASAN}

Profil dari 75 responden penelitian ini dapat ditampilkan pada karakteristik responden. Profil responden diklasifikasikan terdiri dari jenis kelamin, usia, golongan UMKM, penggunaan media online, dan lokasi usaha. Karakteristik responden pada penelitian ini yang terdiri dari 75 responden dipaparkan secara detail dan rinci dalam Tabel 3. sebagai berikut. 
Tabel 3.

Karakteristik Responden

\begin{tabular}{|c|c|c|c|c|}
\hline No & Karakteristik & Klasifikasi & Jumlah & Persentase(\%) \\
\hline \multirow[t]{3}{*}{1} & Jenis Kelamin & Laki - Laki & 53 & 70,70 \\
\hline & & Perempuan & 22 & 29,30 \\
\hline & Jumlah & & 75 & 100 \\
\hline \multirow[t]{6}{*}{2} & Usia & $>50$ Tahun & 5 & 6,7 \\
\hline & & $41-50$ Tahun & 9 & 12 \\
\hline & & $31-40$ Tahun & 9 & 12 \\
\hline & & $21-30$ Tahun & 47 & 62,7 \\
\hline & & $<21$ Tahun & 5 & 6,7 \\
\hline & Jumlah & & 75 & 100 \\
\hline \multirow[t]{4}{*}{3} & Golongan & Usaha Mikro & 40 & 53,3 \\
\hline & UMKM & Usaha Kecil & 22 & 29,3 \\
\hline & & Usaha Menengah & 13 & 17,3 \\
\hline & Jumlah & & 75 & 100 \\
\hline \multirow[t]{4}{*}{4} & Penggunaan & Website \& Media Sosial & 38 & 50,7 \\
\hline & & Media Sosial & 17 & 22,7 \\
\hline & & Tidak Keduanya & 20 & 26,7 \\
\hline & Jumlah & & 75 & 100 \\
\hline \multirow[t]{10}{*}{5} & Lokasi Usaha & Kab. Klungkung & 3 & 4 \\
\hline & & Kab. Denpasar & 44 & 58,67 \\
\hline & & Kab. Tabanan & 1 & 1,33 \\
\hline & & Kab. Jembrana & 1 & 1,33 \\
\hline & & Kab. Karangasem & 1 & 1,33 \\
\hline & & Kab. Buleleng & 1 & 1,33 \\
\hline & & Kab. Gianyar & 6 & 8 \\
\hline & & Kab. Badung & 17 & 22,67 \\
\hline & & Kab. Bangli & 1 & 1,33 \\
\hline & Jumlah & & & 100 \\
\hline
\end{tabular}

Sumber: Data primer diolah, 2019

Dari data yang dikumpulkan pada Tabel 3. berdasarkan jenis kelamin, responden Pelaku UMKM di Provinsi Bali pada penelitian ini responden laki-laki memiliki persentase terbesar, dengan persentase sejumlah 70,70 persen, sedangkan responden jenis kelamin perempuan memiliki persentase sebesar 29,30 persen. Berdasarkan kriteria usia responden Pelaku UMKM di Provinsi Bali berusia 21 sampai dengan 30 tahun mendominasi sebesar 62,7 persen. Pada responden berusia kurang dari 21 tahun dan responden yang berusia lebih dari 50tahun memiliki angka terkecil yaitu masing-masing hanya sebesar 6,7 persen. Berdasarkan golongan UMKM, usaha mikro mendominasi dengan angka persentase sebesar 53,3 persen, sedangkan persentase terendah dimiliki oleh responden golongan menengah dengan persentase sebesar 17,3 persen. Berdasarkan kritria penggunaan media sosial, didominasi oleh responden dengan pengguna website dan media sosial dengan persentase sebesar 50,7 persen, sedangkan persentase terendah dimiliki oleh responden pengguna media sosial saja dengan persentase sebesar 22,7 persen. 
Berdasarkan kritria lokasi usaha, Kabupaten Denpasar memiliki angka tertinggi yaitu sebesar 58,67 persen. Kabupaten Badung mengikuti dengan angka sebesar 22,67 persen.

Tabel 4.

Hasil Uji Validitas Instrumen Penelitian

\begin{tabular}{cllcc}
\hline Variable & & \multicolumn{1}{c}{ Indikator } & $\begin{array}{c}\text { Pearson } \\
\text { Correlation }\end{array}$ & $\begin{array}{c}\text { Ketera } \\
\text { ngan }\end{array}$ \\
\hline Ekspektasi & $\mathrm{X}_{1.1}$ & Perceived usefulness & 0,890 & Valid \\
Kinerja & $\mathrm{X}_{1.2}$ & Job-fit & 0,902 & Valid \\
& $\mathrm{X}_{1.3}$ & Relative advantage & 0,896 & Valid \\
& $\mathrm{X}_{1.4}$ & Outcome Expectation & 0,801 & Valid \\
Ekspektasi & $\mathrm{X}_{2.1}$ & Perceived ease of use & 0,768 & Valid \\
Usaha & $\mathrm{X}_{2.2}$ & Ease of use & 0,884 & Valid \\
& $\mathrm{X}_{2.3}$ & Complexity & 0,862 & Valid \\
Faktor Sosial & $\mathrm{X}_{3.1}$ & Subjective norm & 0,869 & Valid \\
& $\mathrm{X}_{3.2}$ & Image & 0,991 & Valid \\
& $\mathrm{X}_{3.3}$ & Social & 0,821 & Valid \\
Niat & $\mathrm{Y}_{1}$ & Affect & 0,903 & Valid \\
Menggunaka & $\mathrm{Y}_{2}$ & Intention & 0,858 & Valid \\
Search Engine & $\mathrm{Y}_{3}$ & Social & 0,737 & Valid \\
Advertising & $\mathrm{Y}_{4}$ & Perceived Consequencess & 0,878 & Valid \\
\hline
\end{tabular}

Sumber: Data primer diolah, 2019

Uji validitas dilakukan untuk mengetahui kelayakan daftar pertanyaan dalam mendefinisikan suatu variable penelitian. Pengujian validitas instrument menggunakan software SPSS, hasil penelitian ditampilkan pada Table 4. yang menunjukan bahwa angka pearson correlation lebih besar dari 0,3. Hasil tersebut dapat diartikan bahwa penelitian terhadap 75 responden UMKM di Provinsi Bali ini, memiliki instrument variable yang valid dan layak untuk digunakan.

Tabel 5.

Hasil Uji Realibilitas Instrumen Penelitian

\begin{tabular}{lcc}
\hline Variabel & Cronbach's Alpha & $\begin{array}{c}\text { Keteran } \\
\text { gan }\end{array}$ \\
\hline Ekspektasi Kinerja & 0,908 & Reliabel \\
Ekspektasi Usaha & 0,789 & Reliabel \\
Faktor Sosial & 0,836 & Reliabel \\
Niat Menggunakan Search Engine & 0,865 & Reliabel \\
Advertising & & \\
\hline
\end{tabular}

Sumber: Data primer diolah, 2019

Pengujian reliabilitas instrument dilakukan terhadap 75 responden Pelaku UMKM di Provinsi Bali. Reliabilitas menunjukkan sejauh mana suatu alat pengukur dapat dipercaya atau dapat diandalkan. Apabila suatu alat pengukur dipakai dua kali untuk mengukur gejala yang sama dari hasil pengukuran yang diperoleh relatif konsisten, maka alat pengukur tersebut reliabel. Pengujian reliabilitas dalam penelitian ini menggunakan Cronbach's Alpha instrumen dikatakan reliabel apabila berada diatas 0,70 . 
Pengujian ini perlu dilakukan untuk mengkonfirmasi bahwa dalam pengukuruan tidak ada permasalahan. Pengujian ini memanfaatkanfitur uji statistik Cronbach Alpha $(\alpha)$ yang terdapat pada software SPSS. Cronbach's Alpha pada setiap variable memiliki angka yang lebih dari 0,70 . Hasil ini mengartikan bahwa instrument penelitian yang dilakukan pada 75 responden Pelaku UMKM di Provinsi Bali ini merupakan instrument yang memiliki konsistensi dalam pengujian. Bila telah lolos uji realibilitas, alat ukur dalam penelitian dapat diandalkan.

Tabel 6.

Hasil Uji Normalitas Model Regresi

\begin{tabular}{cc}
\hline Variable & Asymp. Sig (2-tailed) \\
\hline Model Regresi & 0,558 \\
\hline Sumber: Data primer diolah, 2019 &
\end{tabular}

Uji normalitas bertujuan untuk mengetahui apakah di dalam sebuah model regresi, variabel terikat, variabel bebas, atau keduanya mempunyai distribusi normal atau tidak. Apabila Asymp. SIg (2-tailed) dan lebih besar dari level of significant yang dipakai $(0,05)$, maka data populasi dikatakan berdistribusi normal. Penelitian yang baik adalah penelitian yang menunjukan model regresi, variabel terikat, variabel bebas atau keduanya menunjukan disribusi yang normal. Metode untuk mengetahui suatu model regresi berdistribusi normal atau tidak adalah dengan melakukan uj normalitas. Tingkatan alpha yang digunakan pada penelitian akan dibandingkan dengan tingkatan signifikasi hasil perhitungan. Asymp. SIg Pada Table 6 data penelitian ini lebih besar dari tingkat signifikasi yaitu 0,05. menunjukan bahwa data pada model regresi berdistribusi normal.

Tabel 7.

Hasil Uji Multikolonieritas

\begin{tabular}{lcc}
\hline \multicolumn{1}{c}{ Variable } & Tolerance & VIF \\
\hline Ekspektasi Kinerja $\left(\mathrm{X}_{1}\right)$ & 0,470 & 2,130 \\
Ekspektasi Usaha $\left(\mathrm{X}_{2}\right)$ & 0,466 & 2,148 \\
Faktor Sosial $\left(\mathrm{X}_{3}\right)$ & 0,544 & 1,838 \\
\hline
\end{tabular}

Sumber: Data primer diolah, 2019

Jika nilai tolerance lebih besar dari 0,1 (10\%) atau VIF kurang dari 10, maka dikatakan tidak ada multikolonieritas. Tabel 7 memaparkan tolerance value variabel memiliki value yang setiap variabel lebih besar dari angka 0,1 . Tabel diatas juga memaparkan bahwa nilai VIF pada hasil uji multikolonieritas ini kurang dari angka 10. Hasil ini menyimpulkan bahwa tidak adanya hubungan multikolonieritas antara variabel bebas dan variabel niat menggunakan search engine advertising.

Tabel 8.

Hasil Uji Heterokedastisitas

\begin{tabular}{lc}
\hline \multicolumn{1}{c}{ Variable } & Sig \\
\hline Ekspektasi Kinerja (X1) & 0,225 \\
Ekspektasi Usaha (X2) & 0,464 \\
Faktor Sosial (X3) & 0,106 \\
\hline Sumber: Data pro
\end{tabular}

Sumber: Data primer diolah, 2019 
Ketidaksamaan varians dan residual pengamatan dan ketidaksamaan varians model regresi dapat diuji menggunakan uji heterokedastisitas. Tabel 8 memperlihatkan bahwa level signifikansi dari variabel mempunyai value signifikansi lebih besar dari angka 0,05. Angka tersebut menandakan model regresi penelitian ini terbebas dari permasalahan heteroskedastisitas.

Tabel 9.

Hasil Analisis Regresi

\begin{tabular}{lccccc}
\hline \multicolumn{1}{c}{ Variable } & $\begin{array}{c}\text { Unstandardized } \\
\text { Coefficients }\end{array}$ & $\begin{array}{c}\text { Standardized } \\
\text { Coefficients }\end{array}$ & t & Sig. \\
& B & Std. Error & Beta & & \\
\hline (Constant) & 1,464 & 1,113 & & 1,315 & 0,193 \\
Ekspektasi Kinerja (X1) & 0,396 & 0,141 & 0,295 & 2,805 & 0,000 \\
Ekspektasi Usaha (X2) & 0.059 & 0.146 & 0,043 & 0,403 & 0,688 \\
Faktor Sosial (X3) & 0,701 & 0.126 & 0,545 & 5,569 & 0,000 \\
Adjusted R square & & & & & 0,615 \\
F Hitung & & & & & 40,383 \\
Sig. F & & & & & \\
\hline Sumber: Data prime & & & & & \\
\hline
\end{tabular}

Sumber: Data primer diolah, 2019

Tabel 9. memaparkan nilai konstanta menunjukan anka sebesar 1,464 yang artinya apabila nilai variabel bebas sama dengan nol, maka variabel terikat niat menggunakan search engine advertising (Y) meningkat sebesar 1,4\%. Nilai variabel ekspektasi kinerja menunjukan tanda positif 0,295 yang menandakan bahwa setiap kenaikan 1\% nilai variabel ekspektasi kinerja memberikan pengaruh peningkatan variabel niat menggunakan search engine advertising sebesar 0,295\%. Nilai variabel ekspektasi usaha menunjukan tanda positif 0,043 yang memberikan arti bahwa peningkatan $1 \%$ nilai pada variabel ekspektasi usaha akan meningkatkan variabel niat menggunakan search engine advertising dengan nilaisebesar 0,043\%. Nilai variabel faktor sosial menunjukan tanda positif 0,545 yang menunjukan bahwa ketika nilai naik $1 \%$ pada variabel fakor sosial akan membuat variabel niat menggunakan search engine advertising meningkat sebesar $0,545 \%$.

Variable terikat niat menggunakan search engine advertising menunjukan nilai $\mathrm{F}$ hitung 40,383 dengan signification value $\mathrm{F}=0,000$, yang tidak lebih besar dari value $\alpha=0,05$. Pengujian F memaparkan bahwa model regresi yang digunakan pada Pelaku UMKM di Provinsi Bali ini merupakan model yang layak. Berdasarkan perhitungan tersebut menunjukan bahwa variabel bebas pada penelitian ini dapat memperhitungkan niat menggunakan search engine advertising pada pelaku UMKM di Provinsi Bali. Besarnya Adjusted $R$ square untuk niat menggunakan search engine advertising memiliki nilai 0,615 . Hasil tersebut menunjukan bahwa variasi niat menggunakan search engine advertising dapat dipaparkan oleh variabel ekspektasi usaha, ekspektasi kinerja, dan social factor, sebesar 61,5\%, sedangkan sebesar 38,5\% dijelaskan oleh faktor-faktor lainya. 
DOI:

Tabel 9. memaparkan bahwa $\mathrm{H}_{1}$ diterima yang diambil dari perhitungan signifikansi t variabel ekspektasi kinerja dengan value 0,000 yang nilainya lebih kecil dari 0,05. Nilai tersebut memaparkan bahwa variabel ekspektasi kinerja memiliki pengaruh yang signifikan dan juga positif terhadap niat menggunakan search engine advertising pada pelaku UMKM di Provinsi Bali Tabel 9 memaparkan bahwa $\mathrm{H}_{1}$ diterima yang diambil dari perhitungan signifikansi $\mathrm{t}$ variabel ekspektasi kinerja dengan value yang nilainya lebih kecil dari 0,05. Perhitungan menunjukan bahwa $\mathrm{H}_{2}$ diterima, yang berarti ekspektasi kinerja berpengaruh positif signifikan terhadap niat menggunakan search engine advertising pada pelaku UMKM di Provinsi Bali. Penelitian niat menggunakan search engine advertising ini, menghasilkan hasil yang sesuai dengan yang dilakukan oleh Isa \& Wong (2015). Responden merasa search engine advertising akan bermanfaat bagi bisnis, meningkatkan produktivitas, meningkatkan efisiensi biaya dan meningkatkan performa penjualan.

Tabel 9. menunjukan signifikasi level dari variabel ekspektasi usaha benilai 0,688 nominalnya lebih besar dari 0,05 . Perhitungan ini menunjukan bahwa $\mathrm{H} 2$ ditolak, yang dapat diartikan bahwa pada penelitian ini ekspektasi usaha tidak berpengaruh terhadap niat menggunakan search engine advertising pada pelaku UMKM di Provinsi Bali. Hasil tersebut memaparkan bahwa semakin tinggi atau rendah tingkat ekspektasi usaha, maka tidak mempengaruhi niat menggunakan search engine advertising. Hal ini menunjukan bahwa Pelaku UMKM di Provinsi Bali belum terbiasa dengan media iklan internet. Berdasarkan hasil tersebut dapat dikatakan bahwa penelitian ini sepaham dengan penelitian yang telah dilakukan oleh Tan et al. (2013), Singh (2015) dan Hakim \& Nurkamid (2017).

Pengukuran pada penelitian ini menunjukan hipotesis ke 3 diterima, signification level $\mathrm{t}$ uji satu sisi pada data menunjukan angka yang lebih kecil dari angka 0,05. Hasil ini memaparkan bahwa faktor sosial berpengaruh positif dan signifikan terhadap niat menggunakan search engine advertising pada pelaku UMKM di Provinsi Bali. Provinsi Bali memiliki cukup banyak enterpreneural center seperti coworking space, inkubasi bisnis dan juga komunitas bisnis. Enterpreneural center ini memegang peran dalam penyebaran informasi. Berdasarkan hasil tersebut, hasil penelitian yang sama juga ditunjukan oleh penelitian sebelumnya dari Isa \& Wong (2015), Hakim \& Nurkamid (2017), dan Tan et al. (2013).

Pengaruh ekspektasi kinerja terhadap niat menggunakan search engine advertising berhubungan positif dengan menciptakan manfaat yang tinggi, peningkatan produktivitas, penigkatan efisiensi dan peningkatan performa penjualan. Hal ini menunjukan bahwa pentingnya fitur-fitur utama dan pembantu pada platform search engine advertising. Pengguna mengharapkan fitur tersebut dapat berjalan lancar dan dapat menargetkan segmentasi pasar yang sesuai dengan produk yang dijual oleh pengguna. Ekspektasi usaha tidak berpengaruh terhadap niat menggunakan search engine advertising. Hasil uji tersebut juga didukung oleh data pada Tabel 3. karakteristik responden dalam penggunaan media online, 49,4\% responden belum menggunakan website. Data tersebut menunjukan bahwa responden belum terbiasa dengan media iklan internet. Hal ini membuat responden belum memiliki pengalaman dan gambaran usaha mengenai search engine 
advertising. Terakhir, berdasarkan hasil penelitian mengenai fakor sosial terhadap niat menggunakan search engine advertising. Keluarga, atau mentor usaha telah mendorong penggunaan search engine advertising. Orang- orang yang telah menggunakan juga dipandang baik dan memiliki prestise yang tinggi.

Provinsi Bali memiliki cukup banyak enterpreneural center seperti coworking space, inkubasi bisnis dan juga komunitas bisnis. Enterpreneural center ini memegang peran dalam penyebaran informasi. Coworking space didominasi di daerah selatan bali seperti seminyak (Kembali Creative Hub), Canggu (Dojo Bali), Denpasar (Colony Creative Hub dan DILO), Jimbaran (Best Coworking) hingga Ubud (Hubud Coworking). Inkubasi bisnis juga merupakan tempat yang cocok untuk peningkatan variabel faktor sosial seperti Inkubasi Bisnis di seluruh Universitas Bali, dan terdapat pula inkubasi bisnis yang dikelola pemerintah yaitu Inkubasi Bisnis Tohpati yang dikelola langsung oleh Kementrian Perindustrian di Bali. Komunitas UMKM pun telah tumbuh pesat baik itu komunitas online (facebook dan whatsapp) hingga offline seperti komunitas UMKM Gapura Digital. Komunitas UMKM Gapura Digital bahkan rutin melakukan pertemuan setiap weekend untuk memberikan informasi mengenai internet marketing hingga search engine advertising. Semakin maju fasilitaas dan ekosistem digital di Bali akan meningkatkan variabel faktor sosial yang pada akhirnya akan meningkatkan niat menggunakan search engine advertising pada UMKM di Provinsi Bali.

Hasil penelitian ini, penting bagi pihak penyedia search engine advertising untuk dapat memberikan fitur-fitur yang bermanfaat bagi peningkatan kinerja pemasaran Pelaku UMKM di Provinsi Bali, kemudian penting untuk memberikan fitur- fitur yang mudah dipelajari dan membangun komunitas sebagai wadah bertukar informasi. Komunitas dapat dikembangkan secara offline maupun online. User interface dan juga user experience dari search engine advertising platform diharapkan dapat dibuat sederhana dan mudah dimengerti.

\section{SIMPULAN}

Ekspektasi kinerja berpengaruh positif signifikan terhadap niat menggunakan search engine advertising pada pelaku UMKM di Provinsi Bali. Ekspektasi usaha tidak berpengaruh pada niat menggunakan search engine advertising pada pelaku UMKM di Provinsi Bali. Pengaruh sosial berpengaruh positif dan signifikan terhadap niat menggunakan search engine advertising pada pelaku UMKM di Provinsi Bali. Saran yang dapat diberikan kepada Penyedia layanan search engine advertising yaitu untuk dapat meningkatkan ekspektasi kinerja dengan meningkatkan fitur-fitur analisis. Fitur analisis ini seperti analisis keyword yang cocok, dan analisis segmentasi calon konsumen. Fitur analisis ini dapat meningkatkan kinerja dari iklan digital. Membangun fitur-fitur yang mendorong peningkatan produktivitas, efektivitas, dan efisiensi biaya pengguna. Hal yang dapat dilakukan lagi adalah memperbaiki algoritma dan bug yang ada pada software. User interface juga seharusnya dibuat agar lebih simple.

Penyedia layanan seharusnya juga lebih memberikan awareness terhadap Pelaku UMKM di Provinsi Bali mengenai kemudahan system yang didapatkan user apabila menggunakan search engine advertising dengan cara membuat blog artikel, help center maupun tutorial penggunaan. Faktor sosial pada Pelaku UMKM di 
Provinsi Bali adalah keluarga, kerabat, pimpinan maupun mentor bisnis. Faktor sosial dilingkungan bisnis merupakan lingkungan yang paling tepat untuk peningkatan niat menggunakan search engine advertising. Hal yang dapat dilakukan adalah membuat komunitas pengguna baik offline maupun online. Komunitas dapat digunakan sebagai wadah untuk berdiskusi antara pengguna maupun calon pengguna search engine advertising. Dengan adanya komunitas juga dapat mengurangi beban dari help center layanan search engine advertising.

Kepada Pelaku UMKM di Provinsi Bali diharapkan untuk memanfaatkan search engine advertising maupun media internet marketing lainya. Pelaku UMKM di Provinsi Bali diharapkan lebih aktif untuk bergabung dengan komunitaskomunitas yang ada disekitarnya. Langkah awal mengaplikasikan seach engine advertising juga dapat dilihat pada platform online seperti youtube tutorial maupun blogs. Kepada penelitian dimasa datang diharapkan dapat melakukan penelitian mengenai niat menggunakan search engine advertising di daerah lainya sebagai perbandingan. Penelitian terhadap internet marketing platform lainya juga dirasa penting untuk dilakukan, seperi facebook advertising dan Instagram advertising. Penelitian selanjutnya diharapkan juga dapat meningkatkan kualitas penelitian dengan meneliti variabel moderasi dan meningkatkan kualitas pertanyaan pada kuesioner.

\section{REFERENSI}

Aleksandar, G., \& Olja, J. (2018). Internet Marketing as A Business Necessity. Internasional Journal of Business and Economic, 16(2), 265-274.

APJII, \& PusKaKom. (2017). Survei Pengguna Internet Tahun 2017. Jakarta.

Badan Pusat Statistik. (2016). Tabel Perkembangan UMKM. Retrieved September 21, 2018, from https://www.bps.go.id/statictable/2014/01/30/1322/tabelperkembangan-umkm-pada-periode-1997--2013.html

Brown, S. ., Dennis, A. R., \& Venkatesh, V. (2016). Predicting Collaboration Technology Use: Integrating Technology Adoption And Collaboration Research. Journal of Management Information Systems, 27(2), 9-53.

Chaffey, D. (2004). E-Business dan E-Commerce Management, Financial TimesPrentice Hall. London.

Chaffey, D., \& Chadwick, F. E. (2016). Digital Marketing Strategy, Impementation and Practice (Sixth Edit). Slovakia: Neografia.

Chong, W., Shafaghi, M., Woollaston, C., \& Lui, V. (2010). B2B E-Marketplace: An E-Marketing Framework For B2B Commerce. Marketing Intelligence \& Planning, 28(3), 310-329.

Edelman, B., Ostrovsky, M., \& Schwarz, M. (2007). Internet Advertising And The Generalized Second-Price Auction: Selling Billions Of Dollars. The American 
Economic Review, 97(1), 242-259.

Farida \& Budi Hermana. (2005). Analisis Proses Adopsi Electronic Payment System dengan menggunakan UTAUT Model: Reliabilitas dan validitas Instrumen Pengukuran. Seminar Nasional " Soft Computing, Intelligent System and Information Technology, (Mm), 1-18.

Hakim, M. M., \& Nurkamid, M. (2017). Model Adopsi UKM di Kudus terhadap Ecommerce. Jurnal Simetris, 8(1), 2252-4983.

Isa, S. M., \& Wong, K. Y. (2015). Age Differences in Behavioral Intention to Use Internet Marketing: A Comparative study between Malaysian and Taiwanese. International Journal for Business and Society, 16(3), 386-396.

Jogiyanto. (2007). Sistem Informasi Keperilakuan. Yogyakarta: Andi Offset.

Kennedy, K., \& Kennedy, B. . (2008). A Small Company's Dilemma: Using Search Engines Effectively For Corporate Sales. Management Research News, 31(10), 737-745.

Laudon, K. C., \& Laudon, J. . (2002). Management Information Systems: Managing the Digital Firm. New Jersey: Prentice Hall.

Madigan, R., Louw, T., Dziennus, M., Graindorge, T., Ortega, E., Graindorge, M., \& Merat, N. (2016). Acceptance of Automated Road Transport Systems (ARTS): An Adaptation of the UTAUT Model. Transportation Research Procedia, 14(0), 2217-2226.

Mufti, A., Destiawati, F., \& Akhirina, T. Y. (2014). Evaluasi Penerimaan Jejaring Sosial Google+ Pada Siswa Sekolah Menengah Atas Di Wilayah Jakarta Selatan. Universitas Indraprasta PGRI.

Mustaqim, R. ., Ari, K., \& Himawat, A. (2018). Analisis Faktor-Faktor Yang Mempengaruhi Niat Penggunaan E-Commerce XYZ Menggunakan Model UTAUT. Jurnal Pengembangan Teknologi Informasi Dan Komputer, 2(7), 2584-2593.

Oswar, T., Suhendra, S., \& Harmoni, A. (2008). Model Perilaku Penerimaan Teknologi Informasi: Pengaruh Variabel Prediktor, Moderating effect, Dampak penggunaan teknologi Informasi Terhadap Produktivitas dan Kinerja Usaha Kecil. Universitas Gunadarma.

Park, C., \& Jun, J. (2003). A Cross Cultural Comparison Of Internet Buying Behavior: Effects Of Internet Usage, Perceived Risks, And Innovativeness. International Marketing Review, 20(5), 534-539. 
Pollack, B. (1999). The State Of Internet Marketing, Direct Marketing. Internasional Journal of Business and Economic, 61(9), 18-21.

Prastika, N. E., \& Purnomo, D. E. (2014). Pengaruh Sistem Informasi terhadap Kinerja Perusahaan Pada Usaha Mikro Kecil dan Menengah (UMKM) di Kota Pekalongan. Jurnal LITBANG Kota Pekalongan, 1(1), 74-102.

Rainer, O., \& Carsten, D. S. (2014). Multichannel Advertising: Does Print Advertising Affect Search Engine Advertising? European Journal of Marketing, 48(9), 1731-1756.

Roberts, M. L., \& Zahay, D. (2012). Internet Marketing: Integrating Online and Offline Strategies. Nashville: South-Western College Pub.

Sharma, D., Gupta, A., Mateen, A., \& Praptap, S. (2017). Making Sense Of The Changing Face Of Google's Search Engine Results Page: An Advertiser's Perspective. Emerald Publishing Limited, 1(1), 1477.

Shin, D. H. (2010). The Effect Of Trust, Security And Privacy In Social Networking: A Securitybased Approach To Understand The Pattern Of Adoption. Interacting With Computers, 22(5), 428-438.Singh, S. (2015). Consumer Behavioral Intention Toward Internet Marketing. Global Journal of Science Frontier Research, 15(1), 0975-5896.

Siswanto. (1997). Memanfaatkan Teknologi Informasi untuk Strategi Keunggulan Bersaing Industri di Perguruan Tinggi Swasta. Makalah Seminar Perguruan Tinggi di Indonesia dalam Transisi Perguruan Tinggi Era Industrialisasi ke Era Informasi. Universitas Atma Jaya.

Srinivansa, S. S., Anderson, R., \& Ponnavolu, K. (2002). Consumers Loyalty In ECommerce And Exploration, If It Is Antecedents And Consequence. Journal of Retailing, 78(1), 41-50.

Sugiyono. (2017). Metode Penelitian Kuantitatif, Kualitatif, dan R\&D. Bandung: Alfabeta.

Tabachnick, B., \& Fidell, L. (2013). Using Multivariate Statistics (6th ed). Boston: Pearson Education.

Tan, K. ., Chong, S. C., \& Lin, B. (2013). Intention to Use Internet Marketing, A comparative study between Malaysians and South Koreans. Kybemetes, 42(6), 889-905.

Vandarajan, R., \& Yadav, M. . (2009). Marketing Strategy In An Internet-Enabled Environment: A Retrospective On The First Ten Years Of JIM And A Prospective On The Next Ten Years. Journal of Interactive Marketing, 23(1), $11-22$. 
Venkatesh, V., Morris, M. ., Davis, G. B., \& Davis, F. . (2003). User Acceptance Of Information Technology: Toward A Unified View. MIS Quarterly, 27(3), 425-478.

Venkatesh, V., Thong, J. Y. L., \& Xu, X. (2012). Consumer Acceptance And Use Of Information Technology: Extending The Unified Theory Of Acceptance And Use Of Technology. MIS Quarterly, 36(1), 157-178.

Venkatesh, V., Thong, J. Y. L., \& Xu, X. (2016). User Acceptance Of Information Technology: A Synthesis And The Road Ahead. MIS Quarterly, 17(5), 328376.

Venkatesh, V., \& Zhang, X. (2016). Unified Theory Of Acceptance And Use Of Technology: US Vs China. Journal of Global Information Technology Management, 13(1), 5-27.

Wirawan, I., Sudibia, K., \& Purbadharmaja. (2015). Pengaruh Bantuan Dana Bergulir, Modal Kerja, Lokasi Pemasaran Dan Kualitas Produk Terhadap Pendapatan Pelaku UMKM Sector Industri Di Kota Denpasar. Jurnal Ekonomi Dan Bisnis Universitas Udayana, 4(1), 01-21.

Yeow, P. H. ., Loo, W. H., \& Chong, S. . (2009). User Acceptance Of Malaysian Government Multipurpose Smartcard Applications. Government Information Quarterly, 26(2), 358-367.

$\mathrm{Yu}$, C.-S. (2012). Factors Affecting Individuals to Adopt Mobile Banking: Empirical Evidence from the UTAUT model. Journal of Electronic Commerce Research, 13(2), 1-20.

Zhou, T. (2011). Understanding Mobile Internet Continuance Usage From The Perspectives Of UTAUT And Flow. Information Development, 27(3), 207218.

Zhou, T., Lu, Y. B., \& Wang, B. (2010). Integrating TTF And UTAUT To Explain Mobile Banking User Adoption. Computers in Human Behavior, 26(4), 760767. 